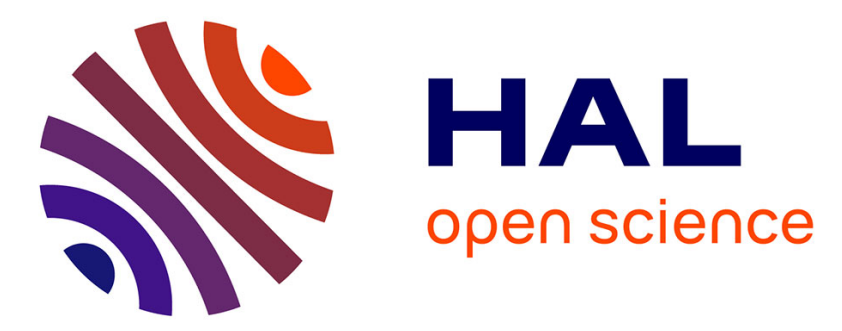

\title{
Fighting Aggregation-Caused Quenching and Leakage of Dyes in Fluorescent Polymer Nanoparticles: Universal Role of Counterion
}

Bohdan Andreiuk, Andreas Reisch, Eduard Bernhardt, Andrey Klymchenko

\section{To cite this version:}

Bohdan Andreiuk, Andreas Reisch, Eduard Bernhardt, Andrey Klymchenko. Fighting AggregationCaused Quenching and Leakage of Dyes in Fluorescent Polymer Nanoparticles: Universal Role of Counterion. Chemistry - An Asian Journal, 2019, Aggregation-Induced Emission, 14 (6), pp.836-846. 10.1002/asia.201801592 . hal-02271515

\section{HAL Id: hal-02271515 \\ https://hal.science/hal-02271515}

Submitted on 26 Aug 2019

HAL is a multi-disciplinary open access archive for the deposit and dissemination of scientific research documents, whether they are published or not. The documents may come from teaching and research institutions in France or abroad, or from public or private research centers.
L'archive ouverte pluridisciplinaire HAL, est destinée au dépôt et à la diffusion de documents scientifiques de niveau recherche, publiés ou non, émanant des établissements d'enseignement et de recherche français ou étrangers, des laboratoires publics ou privés. 


\title{
Fighting aggregation-caused quenching and leakage of dyes in fluorescent polymer nanoparticles: universal role of counterion
}

\author{
Bohdan Andreiuk, ${ }^{1}$ Andreas Reisch, ${ }^{1, *}$ Eduard Bernhardt, ${ }^{2}$ Andrey S. Klymchenko ${ }^{1, *}$ \\ ${ }^{1}$ Laboratoire de Bioimagerie et Pathologies, UMR CNRS 7021, University of Strasbourg, 74 \\ route du Rhin, 67401 Illkirch Cedex, France. \\ ${ }^{2}$ Inorganic Chemistry department of the University of Wuppertal, Gaussstr. 20, 42119 \\ Wuppertal, Germany
}

*Corresponding authors: andrey.klymchenko@unistra.fr; reisch@unistra.fr

\begin{abstract}
Dye-loaded polymer nanoparticles (NPs) emerge as a powerful tool for bioimaging applications, owing to their exceptional brightness and controlled small size. However, aggregation-caused quenching (ACQ) and leakage of dyes at high loading remain important challenges of these nanomaterials. The use of bulky hydrophobic counterions has been recently proposed as an effective approach to minimize ACQ and dye leakage, but the role of counterion structure is still poorly understood. Here, a systematic study based on ten counterions, ranging from small hydrophilic perchlorate up to large hydrophobic tetraphenylborate derivatives, reveals how counterion nature can control encapsulation and emission of a cationic dye (rhodamine B octadecyl ester) in NPs prepared by nanoprecipitation of a biodegradable polymer, poly-lactide-co-glycolide (PLGA). We found that increase in counterion hydrophobicity enhances dye encapsulation efficiency and prevents dye adsorption at the particle surface. Cellular imaging studies revealed that $\geq 95 \%$ encapsulation efficiency, achieved with most hydrophobic counterions (fluorinated tetraphenylborates), is absolutely required, because non-encapsulated dye species at the NPs surface are the origin of dye leakage and strong background in cells. The size of counterions is found to be essential to prevent ACQ, where the largest species, serving as effective spacer between dyes, provide the highest fluorescence quantum yield. Moreover, we found that the most hydrophobic counterions favor dye-dye coupling inside NPs, leading to ON/OFF fluorescence switching of single particles. By contrast, less hydrophobic counterions tend to disperse dyes in the polymer matrix favoring stable emission of NPs. The obtained structure-property relationships validate the counterionbased approach as a mature concept to fight ACQ and dye leakage in the development of advanced polymeric nanomaterials with controlled optical properties.
\end{abstract}

Keywords: aggregation-caused quenching, fluorescent nanoparticles, dye-loaded polymer nanoparticles, bulky hydrophobic counterion, bioimaging. 


\section{TOC}

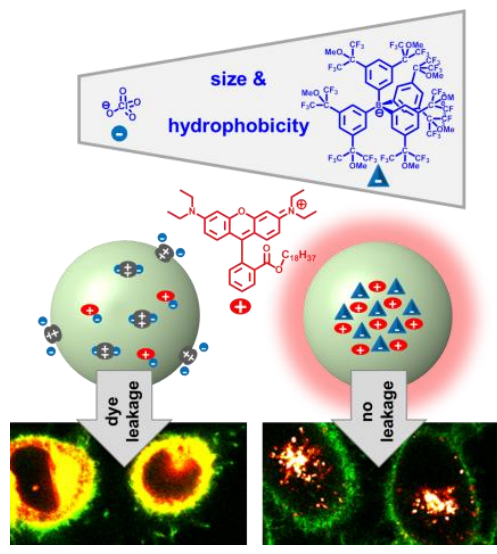

Counterion-enhanced encapsulation and emission: A systematic study based on ten counterions revealed that their size and hydrophobicity is essential to prevent aggregationcaused quenching and ensure efficient encapsulation of a cationic rhodamine dye in polymeric nanoparticles. Here, the use of counterions is established as mature concept for preparation of bright and leakage-free fluorescent nanomaterials for bioimaging applications. 


\section{INTRODUCTION}

In the last decades, fluorescent nanoparticles (NPs) have grown from a scientific curiosity to a reliable tool in bioimaging ${ }^{[1]}$ and theranostics. ${ }^{[2]}$ Although quantum dots have been the most popular class of luminescent NPs for a long time, ${ }^{[3]}$ organic NPs become more and more attractive due to their biodegradability and high versatility. ${ }^{[4]}$ Intensive work in the field generated a number of families of fluorescent organic NPs, such as conjugated polymer NPs, ${ }^{[1 \mathrm{c}]}$ dye-loaded polymer ${ }^{[2 \mathrm{~h}, 4 \mathrm{a}]}$ and lipid $^{[5]} \mathrm{NPs}$ as well as dye-based NPs, ${ }^{[6]}$ notably using aggregation-induced emission (AIE) dyes. ${ }^{[2 \mathrm{~h}, 7]}$ Among these families, dye-loaded polymer NPs are of particular interest because they combine high stability, potential biodegradability (of the polymer matrix) and capacity to co-encapsulate other contrast agents and drugs. ${ }^{[2 \mathrm{~h}, 8]}$ However, this class of NPs still faces two major challenges - inefficient encapsulation of fluorophores and aggregation-caused quenching (ACQ) of these dyes. Several studies have shown that higher hydrophobicity of the dyes increases their encapsulation efficiency in hydrophobic matrices and stability towards dye leakage ${ }^{[9]}$ However even the most hydrophobic dyes still suffer from incomplete encapsulation at loadings higher than $1 \%(\mathrm{w} / \mathrm{w}) .{ }^{[10]}$ On the other hand, a fruitful direction to fight ACQ is to design fluorophores exhibiting efficient emission in the solid state. ${ }^{[7 b, 11]}$ The direct approach is introducing bulky groups ${ }^{[12]}$ and polymer chains ${ }^{[13]}$ to the fluorophore, which can prevent pi-pi stacking of dyes in the polymeric matrix. However, this method has limitations in terms of fluorophore structure and requires additional synthetic efforts. AIE has become a highly popular and efficient approach to prevent ACQ of dyes in the solid state ${ }^{[7,14]}$ although this method is focused on NPs presenting a core of pure AIE dyes. ${ }^{[2 \mathrm{~g}-}$ $\mathrm{i}, 15]$

Recently we introduced an efficient approach to fight ACQ in dye-loaded polymer NPs using bulky hydrophobic counterions as spacers for ionic dyes. ${ }^{[8,16]}$ We have shown that the bulky counterion tetrakis(pentafluorophenyl)borate (F5-TPB) in the ion pair with rhodamine B octadecyl ester (R18) enables dye encapsulation with minimal ACQ, resulting in 40-nm polymer NPs that are 5-100-fold brighter than corresponding quantum dots. ${ }^{[8,16-17]}$ This approach was proven to be compatible with other cationic dyes, such as cyanines, leading to a development of a method for long-term rainbow cell barcoding. ${ }^{[18]}$ Moreover, F5-TPB counterion can be replaced with another fluorinated tetraphenylborate ${ }^{[18]}$ and a fluorinated aliphatic aluminate. ${ }^{[19]}$ Finally, the counterion-based approach was recently applied to create an unprecedented giant light-harvesting nanoantenna that allowed detection of single molecules in ambient light conditions, ${ }^{[20]}$ and amplified detection of nucleic acids. ${ }^{[21]}$

These bulky hydrophobic counterions belong to the class of weakly coordinating anions, characterized by high charge delocalization, large size, absence of basic sites, presenting mainly fluorine or hydrogen at their anion surface. ${ }^{[22]}$ Primary applications of weakly coordinating anions include catalysis, ${ }^{[23]}$ electrochemistry, ${ }^{[24]}$ ionic liquids, ${ }^{[25]}$ microporous materials, ${ }^{[26]}$ lithium batteries, ${ }^{[27]}$ ion-selective electrodes, ${ }^{[28]}$ ion sensors, ${ }^{[29]}$ solar cells ${ }^{[30]}$ and organic light-emitting diodes. ${ }^{[31]}$ It has been already known, that the nature of a counterion can strongly affect the properties of cationic fluorophores in solutions, ${ }^{[32]}$ lipid droplets ${ }^{[5,33]}$ and counterion-assembled NPs made exclusively of dyes ${ }^{[34]}$. However, it remains unclear how the structure of the counterion affects encapsulation and emission of dyes inside polymer NPs. In particular, it concerns the capacity of counterion to (1) operate as a phase transfer agent, 
favoring encapsulation of cationic species into hydrophobic polymer matrix and (2) prevent dyes from pi-pi stacking, thus minimizing ACQ. Addressing these issues would open the routes to new nanomaterials with high brightness and complete encapsulation of cationic cargo features of utmost importance for bioimaging, theranostics and drug delivery. Moreover, understanding the ways counterions structure tunes NP properties, like particle blinking and energy transfer efficiency would enable preparation of variety of advanced materials with desired properties without changing the polymer matrix. ${ }^{[17 a]}$

In the present work we prepared ion pairs of a hydrophobic octadecyl-rhodamine B (R18) with ten counterions of different sizes and hydrophobicities (Fig. 1), ranging from small hydrophilic perchlorate to large hydrophobic tetraphenylborate (TPB) derivatives, and encapsulated them into PLGA (poly-lactide-co-glycolide, biodegradable polymer) NPs. The properties of the counterions, namely their size and hydrophobicity, were found to define to a large extent the properties of the obtained polymer NPs, like their size, dye encapsulation efficiency, fluorescence quantum yield, fluorescence anisotropy, dye-dye energy migration, as well as single-particle brightness and blinking.

\section{MATERIALS AND METHODS}

\section{Materials}

PLGA (lactide 50 mole $\%$, glycolide 50 mole $\%$, Mn 24,000; PDI 1.7), Sodium tetrakis[3,5bis(1,1,1,3,3,3-hexafluoro-2-methoxy-2-propyl)phenyl]borate trihydrate (F12-TPB), Potassium tetrakis[3,5-bis(trifluoromethyl)phenyl]borate (F6-TPB), Potassium hexafluorophosphate $\left(\mathrm{PF}_{6}\right)$, Sodium tetrafluoroborate $\left(\mathrm{BF}_{4}\right)$ and rhodamine $\mathrm{B}$ octadecyl ester perchlorate $\left(\mathrm{R} 18 / \mathrm{ClO}_{4}\right)$ were purchased from Sigma-Aldrich and used as received. Lithium Tetrakis(pentafluorophenyl)borate ethyl ether complex (F5-TPB) was purchased from TCI and used as received. Tris(pentafluorophenyl)borane and tetramethylammonium solution (25\% w/w, aqueous) were purchased from Alfa Aesar. $\mathrm{KB}(\mathrm{CN})_{4}, \mathrm{~KB}\left(\mathrm{CF}_{3}\right)_{4}$ and $\mathrm{KB}_{21} \mathrm{H}_{18}$ were synthesized as described previously ${ }^{[35]}$. Synthesis of F5-3PB-OH is described in Supporting Information.

\section{Methods}

NMR spectra were recorded at $20{ }^{\circ} \mathrm{C}$ on Bruker Avance III $400 \mathrm{MHz}$ and Bruker Avance III $500 \mathrm{MHz}$ spectrometers. Mass spectra were obtained using an Agilent Q-TOF 6520 mass spectrometer.

General procedure for synthesis of R18/counterion pairs. $10 \mathrm{mg}(0.012 \mathrm{mmol})$ of Rhodamine B octadecyl ester perchlorate $\left(\mathrm{R} 18 / \mathrm{ClO}_{4}\right)$ was mixed with 3-10 equivalents of the appropriate counterion salt in DCM and the mixture was sonicated for 5 minutes. Products of ion exchange were purified on preparative TLC plates using DCM/MeOH mixtures as eluent. Results are summarized in the Table S1. Other details are given in Supporting Information. 
Estimation of counterion sizes was done with Chem3D software using MM2 method for structure energy minimization.

Preparation of fluorescent NPs. PLGA was dissolved at $2 \mathrm{mg} / \mathrm{ml}$ in acetonitrile containing different amounts of rhodamine-counterion pairs ( 5 and $50 \mathrm{mM}$ with respect to the polymer). These solutions were injected with a pipette under stirring to a ninefold volume excess of 20 $\mathrm{mM}$ phosphate buffer ( $\mathrm{pH}$ 7.4). The obtained nanoparticle solution was then rapidly diluted fivefold with the same buffer.

Characterization of NPs. Absorption and emission spectra were recorded using Cary 4000HP Scan ultraviolet-visible spectrophotometer (Varian) and FluoroMax-4 spectrofluorometer (Horiba Jobin Yvon) equipped with a thermostated cell compartment, respectively. Steadystate fluorescence anisotropy was measured on a Fluorolog spectrofluorometer (Horiba Jobin Yvon). DLS measurements were performed on a Zetasizer Nano ZSP.

Fluorescence quantum yields (QYs) were measured using rhodamine B in methanol $(\mathrm{QY}=$ $0.70^{[36]}$ ) as a reference. The absorption of NPs solution did not exceed 0.2 , and the fluorescence spectra of both the reference and the NPs were measured at the same excitation wavelength and slits width. Absorption spectra, containing contribution from scattering of large NPs, were corrected for scattering using Origin software.

Encapsulation of ion pairs inside nanoparticles was measured as the ratio of dye quantity (in moles) in the sample after and before dialysis (MEMBRA-CEL MD34 14x100 membrane, MWCO 14000) versus $1 \mathrm{mM}$ beta-cyclodextrin solution in water as recipient medium according to a protocol below:

Absorption spectra of freshly-prepared NPs was measured, then $450 \mu \mathrm{L}$ of NP solution were mixed with $550 \mu \mathrm{L}$ of $1 \mathrm{mM}$ beta-cyclodextrin solution, and the resulting solution was dialyzed for 24 hours with $1 \mathrm{mM}$ beta-cyclodextrin solution as a recipient medium. After dialysis, the solution inside the membrane was recovered, and its volume and absorption spectra were measured to obtain values of dye encapsulation.

Calculation of LogP $P_{\text {HwA. }}$ Method A: Mutually presaturated phases A (heptane), $200 \mu 1$, and $\mathrm{B}$ (water/acetonitrile 1/1), $1 \mathrm{ml}$, were placed into an Eppendorf tube, and $5 \mu \mathrm{l}$ of $\sim 0.3 \mathrm{mM}$ acetonitrile solution of a R18-counterion ion pair were added to the aqueous phase (B). The phases were vigorously vortexed and afterwards centrifuged to partition the phases. Afterwards $50 \mu \mathrm{l}$ of each phase were added to $1 \mathrm{ml}$ of EtOH and R18 concentration in the resulting solutions was measured. $\log \mathrm{P}_{\mathrm{HWA}}$ was calculated as a logarithm of the ratio of dye concentration in phase A (apolar) to dye concentration in phase B (polar).

Method A was applied to R18/F5-3PB-OH, R18/B ${ }_{21} \mathrm{H}_{18}, \mathrm{R} 18 / \mathrm{F} 5-\mathrm{TPB}, \mathrm{R} 18 / \mathrm{F} 6-\mathrm{TPB}$ and R18/F12-TPB ion pairs, however it was not suitable for less hydrophobic ion pairs, whose absorption in heptane phase was below detection limit. For the less hydrophobic ion pairs method B was developed.

Method B: Mutually presaturated phases A (heptane), $1 \mathrm{ml}$, and B (water/acetonitrile 1/1), 1 $\mathrm{ml}$, were placed into an Eppendorf tube, and $25 \mu \mathrm{l}$ of $\sim 0.3 \mathrm{mM}$ acetonitrile solution of a R18counterion ion pair were added to the aqueous phase (B). The phases were vigorously vortexed 
and then centrifuged to partition the phases. Afterwards each phase was carefully collected and the concentration of dye in each phase was measured without dilution. $\log \mathrm{P}_{\mathrm{HWA}}$ was calculated as a logarithm of the ratio of dye concentration in phase $\mathrm{A}$ to dye concentration in phase $\mathrm{B}$.

Method B was applied to $\mathrm{R} 18 / \mathrm{ClO}_{4}, \mathrm{R} 18 / \mathrm{BF}_{4}, \mathrm{R} 18 / \mathrm{PF}_{6}, \mathrm{R} 18 / \mathrm{B}(\mathrm{CN})_{4}$ and $\mathrm{R} 18 / \mathrm{B}\left(\mathrm{CF}_{3}\right)_{4}$ ion pairs.

Single-particle measurements were performed in the TIRF (Total Internal Reflection Fluorescence) mode using a home-made wide-field setup based on an Olympus IX-71 microscope with an oil immersion objective. A DPPS (Cobolt) continuous wave laser emitting at $532 \mathrm{~nm}$ was used for excitation. The laser intensity was changed between 0.08 and $0.5 \mathrm{~W} \mathrm{~cm}^{-2}$ by using a polarizer and a half-wave plate $(532 \mathrm{~nm})$. The fluorescence signal was recorded with an EMCCD camera (ImagEM Hamamatsu).

Cellular studies. KB cells were grown in DMEM (Gibco-Invitrogen), supplemented with 10\% fetal bovine serum (Dominique Dutscher) and 1\% MEM vitamins, $1 \%$ L-glutamine, $1 \%$ MEM non-essential aminoacids and $0.4 \%$ antibiotic gentamicin at $37{ }^{\circ} \mathrm{C}$ in humidified atmosphere containing $5 \% \mathrm{CO}_{2}$. Cells were seeded onto 8-chambered LabTek at a density of $3 \times 10^{4}$ cells per well $24 \mathrm{~h}$ before the microscopy measurement. For imaging, the culture medium was removed and the attached cells were washed with Opti-MEM (Gibco-Invitrogen) three times. Next, a freshly prepared solution of NPs, loaded at 5 and $50 \mathrm{mM}$ with different R18-counterion ion pairs, prepared as described above, were diluted 20 times in Opti-MEM, added to the cells and incubated for 3 hours. Cell membrane staining with wheat-germ agglutinin-Alexa488 was done for $5 \mathrm{~min}$ at room temperature before the measurements. Fluorescence imaging was performed on a Leica TSC SPE confocal microscope using a $63 \times$ oil immersion objective. The different channels were recorded as follows: excitation $488 \mathrm{~nm}$, emission recorded from 495 to $560 \mathrm{~nm}$ for wheat-germ agglutinin-Alexa488; excitation $561 \mathrm{~nm}$, emission recorded from 570 to $650 \mathrm{~nm}$ for dye-loaded NPs.

\section{RESULTS AND DISCUSSION}

\section{Selection of the counterions and characterization of their dye salts}

The counterions were selected to achieve maximal variability in terms of size and hydrophobicity. Thus, our smallest counterions $\left(\mathrm{ClO}_{4}\right.$ and $\left.\mathrm{BF}_{4}\right)$ were $\sim 0.33 \mathrm{~nm}$ in diameter, whereas the largest one (F12-TPB) was $\sim 1.6 \mathrm{~nm}$ (Figure 1), according to molecular modeling. We used 10 counterions in order to achieve gradual variation of the size. Larger size of counterion should also increase delocalization of the charge. ${ }^{[22]}$ As the size was systematically increased by additional fluorinated groups (except $\mathrm{B}_{21} \mathrm{H}_{18}$ ), we could consider that increase in the size (i.e. increase in the fluorination level) should directly increase hydrophobicity of the counterion. Indeed, fluorination of organic molecules increases significantly their hydrophobicity, which is sometimes called super-hydrophobicity. ${ }^{[37]}$ 


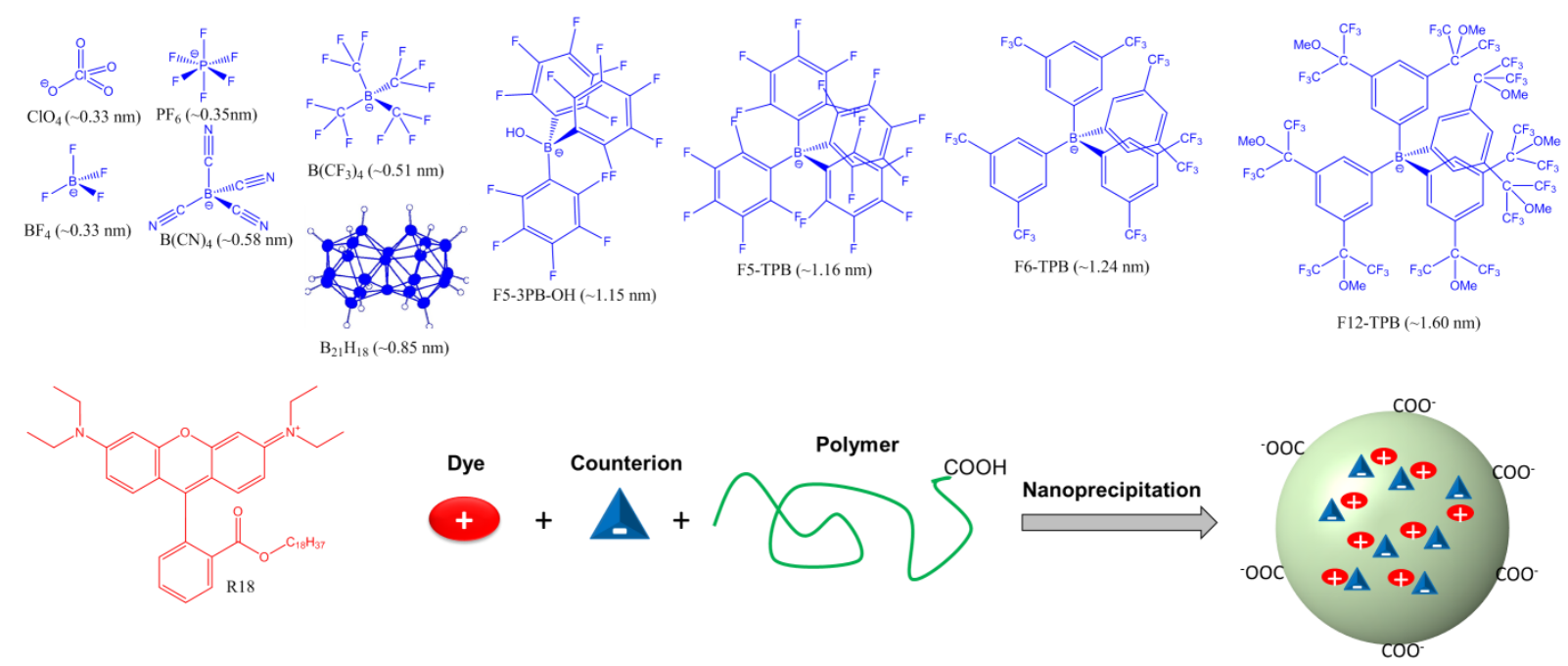

Figure 1. Counterions and R18 dye used for preparation of dye-loaded fluorescent polymeric nanoparticles.

Using these counterions, we prepared the corresponding 10 salts with cationic rhodamine B octadecyl ester (R18). The synthesis of these salts was based on ion exchange, where the starting material, $\mathrm{R} 18$ salt with $\mathrm{ClO}_{4}$ anion $\left(\mathrm{R} 18 / \mathrm{ClO}_{4}\right)$, was mixed in organic solvent (dichloromethane) with an excess of a salt of an anion of interest followed by purification through chromatography. Thin later chromatography (TLC) of these salts in dichloromethane revealed remarkable variation of their mobility on silica gel. While R18 salts with $\mathrm{ClO}_{4}$ and $\mathrm{BF}_{4}$ did not move on TLC at all, $\mathrm{PF}_{6}, \mathrm{~B}(\mathrm{CN})_{4}$ and $\mathrm{F} 5-3 \mathrm{~PB}-\mathrm{OH}$ showed some non-negligible $\mathrm{Rf}$ values (Figure 2A). Much higher mobility was observed for all other studied counterions with Rf increasing in the following order: $\mathrm{B}\left(\mathrm{CF}_{3}\right)_{4}<\mathrm{B}_{21} \mathrm{H}_{18} \sim \mathrm{F} 5-\mathrm{TPB}<\mathrm{F} 6-\mathrm{TPB}<\mathrm{F} 12-\mathrm{TPB}$ (Table $\mathrm{S} 2$ ). Thus, as a general trend, the salts having larger anions and higher values of fluorination showed higher mobility, which could be explained by lower polarity of these salts. To verify the variation of polarity and its link to the hydrophobicity of these salts, we studied distribution of the dye salts in a two-phase system composed of three solvents: heptane, acetonitrile and water. In this case heptane and water form, respectively, highly apolar and polar phases, whereas acetonitrile was used to improve the solubility of the dye salts in water. The obtained logarithm of partitioning constants in this ternary solvent mixture $\left(\log \mathrm{P}_{\mathrm{HWA}}\right)$ showed gradual changes as a function of the counterion (Figure 2B, Table S3). The lowest values were observed for small hydrophilic anions $\mathrm{ClO}_{4}$ and $\mathrm{BF}_{4}$, and $\mathrm{Log} \mathrm{P}_{\mathrm{HWA}}$ increased gradually with the size and fluorination level of the counterion, reaching the highest values for F6-TPB and F12-TPB. We should note that $\mathrm{B}_{21} \mathrm{H}_{18}$, which does not have fluorines at all, also showed relatively high values of $\log \mathrm{P}_{\mathrm{HWA}}$, indicating that these boron clusters are also remarkably hydrophobic. The $\log \mathrm{P}_{\mathrm{HWA}}$ values correlated well with the Rf values obtained from TLC, namely higher Rf values usually corresponded to higher values of $\log \mathrm{P}_{\text {HWA }}$. The only exception was F5-3PB$\mathrm{OH}$, which showed unexpectedly low Rf values, probably due to interactions of its $\mathrm{OH}$ group with silica. Overall, our TLC and two-phase distribution studies showed that larger and more fluorinated counterions form significantly more hydrophobic salts with the R18 dye, which should affect their further encapsulation into the hydrophobic polymer matrix of nanoparticles. 


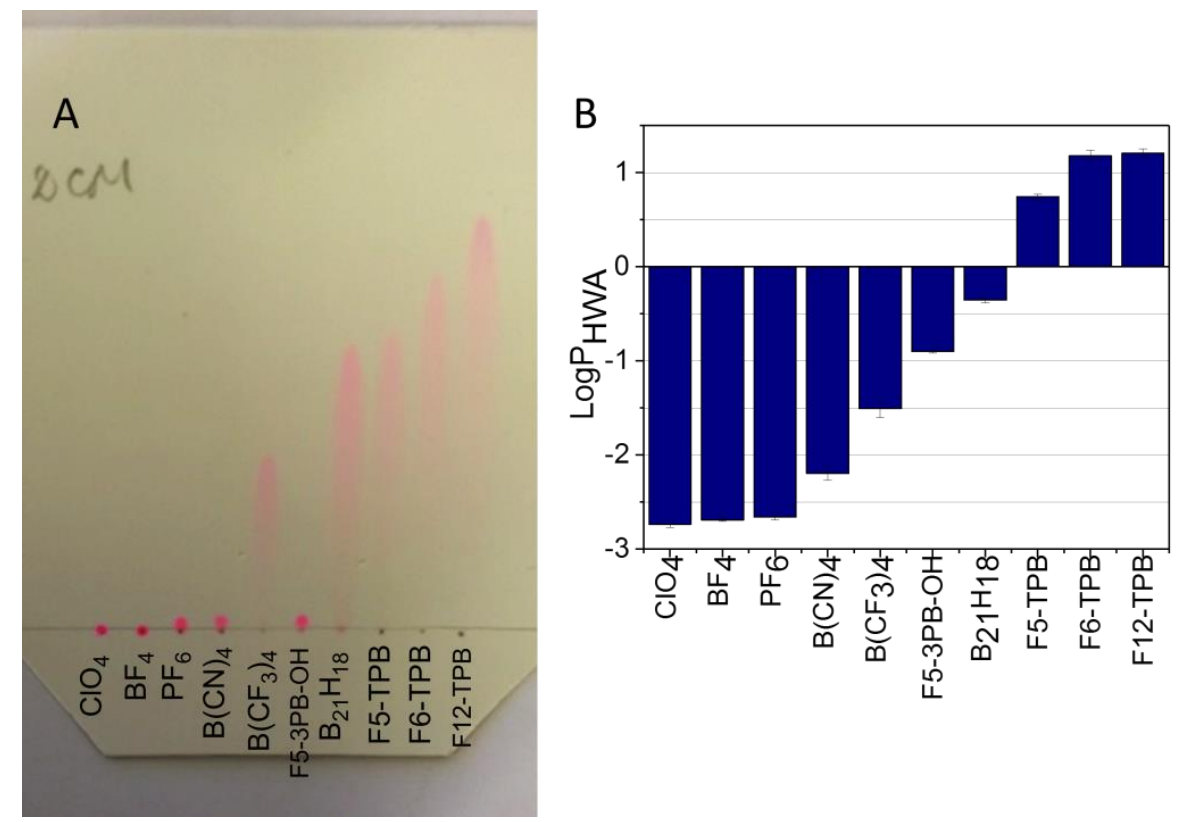

Figure 2. (A) Thin layer chromatography plate of R18 salts with different counterions, run with dichloromethane as eluent. (B) $\log \mathrm{P}_{\mathrm{HWA}}$ values measured for the studied ion pairs.

\section{Dye-loaded NPs and their properties}

All 10 dye salts were then encapsulated in PLGA polymer NPs through nanoprecipitation of PLGA and the dye salt in organic solvent into aqueous solution at neutral $\mathrm{pH} .{ }^{[8,16,38]}$ The PLGA nanoparticles were formulated at 5 and $50 \mathrm{mM}$ dye loading with respect to the polymer. At low dye loading $(5 \mathrm{mM})$, the hydrodynamic diameter of NPs, as estimated by DLS, was $40-50 \mathrm{~nm}$ for all the studied counterions (Table S4). At $50 \mathrm{mM}$, only dye salts with large hydrophobic counterions led to small $(40-60 \mathrm{~nm}$ ) and colloidally stable particles (Figure 3 and S20, Table $\mathrm{S} 5)$. By contrast, for all small hydrophilic counterions, such as $\mathrm{ClO}_{4}, \mathrm{BF}_{4}, \mathrm{PF}_{6}$ and $\left.\mathrm{B}(\mathrm{CN})_{4}\right)$, relatively large particles (>100 nm) were observed. Moreover, such NPs appeared colloidally unstable and precipitated overnight. These data suggest that high loading of dyes salts with small hydrophilic counterions produces aggregation of NPs. Previously, we showed this phenomenon only for NPs loaded with $\mathrm{R} 18 / \mathrm{ClO}_{4}$ salt, which, according to DLS and electron microscopy data, displayed aggregation and large size, in contrast to those loaded with R18/F5TPB. ${ }^{[16]}$ Here, we show that the problem is observed for variety of small hydrophilic anions. Our observations support the hypothesis that during nanoprecipitation the ion pair of R18 with these anions dissociated in water giving cationic amphiphile R18. The latter may adsorb at the surface of newly formed NPs and neutralize their negative surface charge. ${ }^{[16]}$ Our previous works showed that the driving force for the formation of small polymeric NPs is the negative charge of the polymer, which ensures efficient repulsion of the newly formed NPs. Therefore, cationic R18, dissociated in water from its small hydrophilic counterion, could neutralize the negative charge of NPs, thus decreasing their colloidal stability and provoking their aggregation. On the other hand, the ion pair of R18 with bulky hydrophobic counterions probably cannot dissociate in water and acts as an apolar entity, favoring dye encapsulation without disturbing formation of small NPs. The latter is in line with the fact that loading of R18 
with F5-TPB did not change the surface charge of PLGA NPs, indicating that bulky hydrophobic counterion F5-TPB prevents adsorption of R18 on NPs surface, but favors its encapsulation. ${ }^{[16]}$

To further clarify this issue, we studied the encapsulation efficiency of dye salts inside NPs. To this end, $50 \mathrm{mM}$ dye-loaded NPs were dialyzed against $1 \mathrm{mM}$ solution of betacyclodextrin, which proved to be an efficient method to wash out poorly encapsulated R18. ${ }^{[18]}$ First, we confirmed by absorption spectra that beta-cyclodextrin could solubilize R18/ClO4 dye salt (Figure S21). We found that the remaining dye fraction after dialysis (encapsulation efficiency) depended strongly on the nature of the counterion. Indeed, the encapsulation efficiency was lowest for the small hydrophilic counterions $\mathrm{ClO}_{4}, \mathrm{BF}_{4}, \mathrm{PF}_{6}$ and $\mathrm{B}(\mathrm{CN})_{4}$ and highest for the most hydrophobic counterions (Figure 3, Table S5). These results confirmed our hypothesis that hydrophobic counterions minimize adsorption of R18 salts on the particle surface and favor their encapsulation.

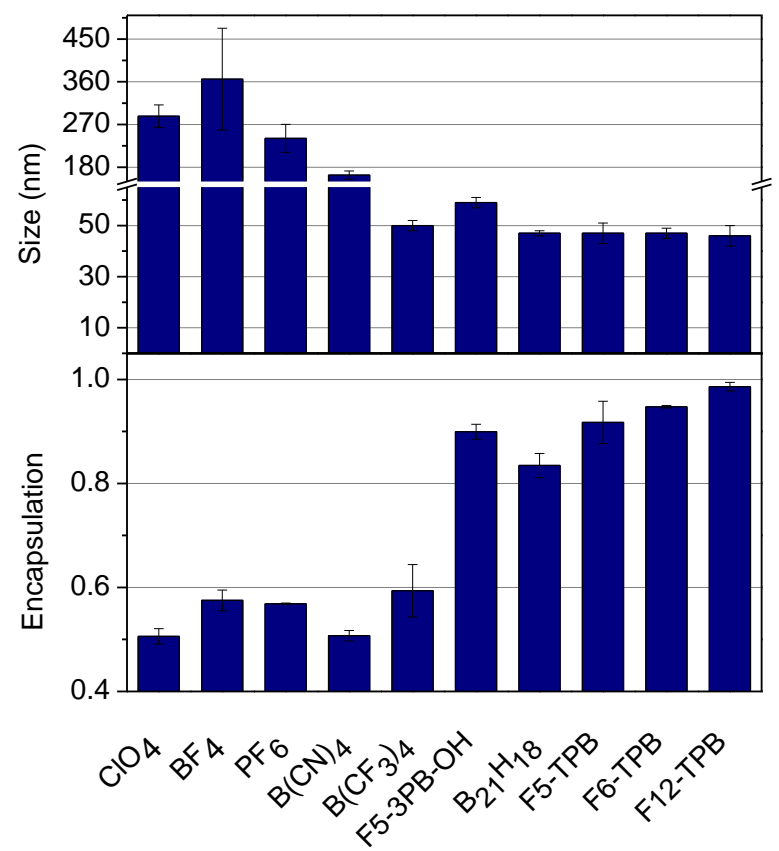

Figure 3. Hydrodynamic diameter of dye-loaded PLGA NPs according to DLS and encapsulation efficiency of $\mathrm{R} 18$ salts with different counterions. Dye salt loading was $50 \mathrm{mM}$ with respect to polymer.

Then we studied optical properties of the obtained dye-loaded NPs. Fluorescence spectra of PLGA NPs loaded at $50 \mathrm{mM}$ with R18 dye salts showed significant variations in the intensity (Figure 4A) and slight changes in the band position (Figure S22, Table S6) as a function of the counterion. Indeed, for the bulky hydrophobic counterions $\left(\mathrm{B}_{21} \mathrm{H}_{18}\right.$, F5-TPB, F6-TPB, F12TPB), NPs displayed stronger fluorescence intensity, while the blue shifted emission was systematically observed for their fluorinated analogues (F5-TPB, F6-TPB, F12-TPB). For this loading, fluorescence quantum yields (QYs) showed clear dependence on the nature of the counterion (Figure 4B, Table S5). The lowest QY values were observed for small hydrophilic anions $\left(\mathrm{ClO}_{4}, \mathrm{BF}_{4}, \mathrm{PF}_{6}\right.$ and $\left.\mathrm{B}(\mathrm{CN})_{4}\right)$, whereas the highest values corresponded to the most hydrophobic and bulky anions, namely $\mathrm{B}_{21} \mathrm{H}_{18}$, F5-TPB, F6-TPB, F12-TPB. By contrast, the QY values were high (>50\%) for all $5 \mathrm{mM}$ dye-loaded NPs independently of counterion (Table 
S4). In absorption spectra, $5 \mathrm{mM}$ dye-loaded NPs showed relatively narrow bands for all the counterions, being clearly different form aggregates of R18/ClO4 in water (Figures S23-S25). This indicates that at low dye loading the dyes salts, independently of the counterion, were probably well encapsulated inside polymer matrix without signs of dye aggregation, thus explaining high QYs. By contrast, at $50 \mathrm{mM}$ loading, R18 with small hydrophilic counterions showed broadened and red-shifted absorption spectra, close to that of $\mathrm{R} 18 / \mathrm{ClO} 4$ aggregates in water (Figure S26, Table S6). In case of medium-sized counterions $\left(\mathrm{B}\left(\mathrm{CF}_{3}\right)_{4}\right.$ and F5-3PB-OH, Figure S27) and especially bulky hydrophobic counterions $\left(\mathrm{B}_{21} \mathrm{H}_{18}, \mathrm{~F} 5-\mathrm{TPB}, \mathrm{F} 6-\mathrm{TPB}, \mathrm{F} 12-\right.$ TPB, Figure S28) the absorption spectra looked more narrow and significantly red shifted with respect to the $\mathrm{R} 18 / \mathrm{ClO} 4$ aggregates in water and their maxima were close to that of $\mathrm{R} 18 / \mathrm{ClO} 4$ in methanol (Table S6). These results suggest that at high loading R18 with small hydrophilic anions undergo strong aggregation that leads to dye self-quenching (ACQ). By contrast, in case of bulky hydrophobic counterions, ACQ of dyes inside NPs is much less pronounced despite the high loading. These observations corroborate with our earlier report ${ }^{[16]}$ showing that the R18 salt with F5-TPB counterion is much less quenched in PLGA NPs than the R18 salt with $\mathrm{ClO}_{4}$. Here, we show this tendency for a large range of anions, which suggests that bulky and hydrophobic nature is a key to preventing aggregation-caused quenching of cationic R18. Independently of their chemical structure, these anions play a role of spacer for the cationic rhodamine dye, thus preventing formation of non-fluorescent pi-pi stacked aggregates. On the other hand, these results also suggest that fluorination of the counterion is important, but not absolutely required condition, because very good QY was also obtained for ion pair with $\mathrm{B}_{21} \mathrm{H}_{18}$ anion, which has no fluorines at all. Based on its high LogP $\mathrm{P}_{\mathrm{HWA}}$ and $\mathrm{Rf}$ values, we could speculate that the combination of high hydrophobicity and large size of $\mathrm{B}_{21} \mathrm{H}_{18}$ is crucial to achieve effective prevention of aggregation-caused quenching. The R18 salt with $\mathrm{B}\left(\mathrm{CF}_{3}\right)_{4}$ anion exhibited intermediate values of QY, probably due to its intermediate values of size and hydrophobicity in comparison to other studied anions. It is important to note that purification of these NPs by dialysis in the presence of beta-cyclodextrin improved quantum yields for all small hydrophilic anions, although the obtained QY values never reached those for the bulky hydrophobic counterions (Figure 4B, Table S5). We expect that a poorly encapsulated fraction of dyes is probably self-quenched at the NP surface, so that its removal improves the QY of NPs. Importantly, this purification procedure does not change the QY values for NPs with bulky hydrophobic anions, in line with their capacity to encapsulate efficiently the R18 dye. 

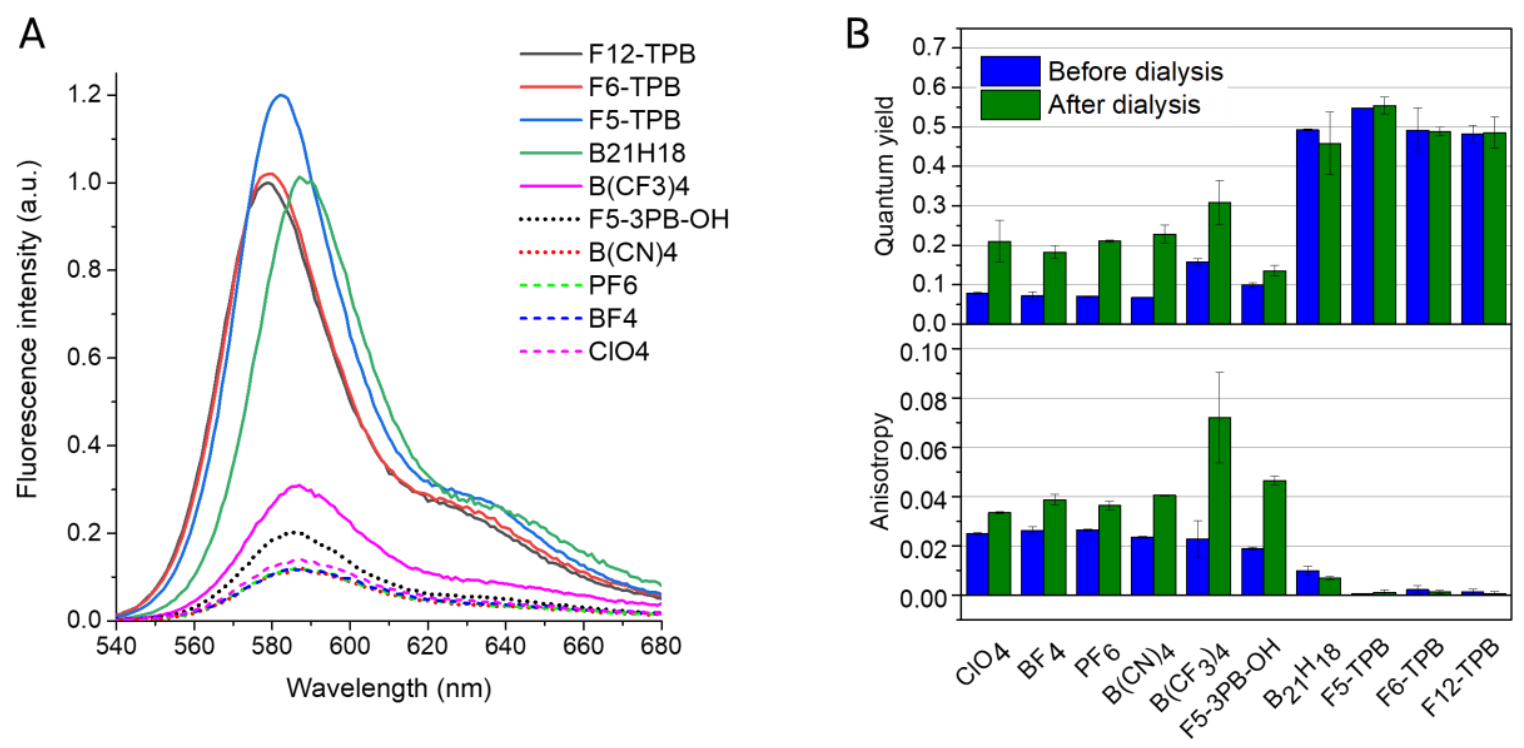

Figure 4. Fluorescence properties of PLGA NPs loaded at $50 \mathrm{mM}$ of R18 dye salts with different counterions. (A) Fluorescence spectra of the dye-loaded NPs before the dialysis. The intensity was normalized to the corresponding fluorescence quantum yield. (B) Fluorescence quantum yield and anisotropy of the dye-loaded NPs before and after dialysis.

When dyes are localized in close proximity within the polymer, they may start communicating by so-called excitation energy transfer (EET). This process can be readily monitored by fluorescence anisotropy, because EET leads to loss of anisotropy. ${ }^{[16]}$ In the rigid polymer matrix, where fluorophores do not undergo molecular rotation, EET is the only mechanism of anisotropy loss. The lower are the values of anisotropy, the larger population of dyes is involved in EET. Our data show that extremely low values of anisotropy $(\leq 0.002)$ were observed only for four counterions: F5-TPB, F6-TPB, F12-TPB and $\mathrm{B}_{21} \mathrm{H}_{18}$ (Figure 4B, Table S5). For all other counterions, the anisotropy value was much higher, and the purification of NPs by dialysis further increased it. This effect was especially pronounced for $\mathrm{B}\left(\mathrm{CF}_{3}\right)_{4}$, where the value reached 0.071, which was $\sim 100$-fold higher than those observed for the three fluorinated TPB counterions. This result underlines that the counterion can strongly alter organization of dyes inside the polymer matrix. Thus, in line with our original works on F5TPB, the bulky hydrophobic (TPB) counterions tend to organize the dyes in form of clusters where the dyes undergo very fast EET. ${ }^{35,49}$ Our recent work suggested that with F5-TPB, EET within R18 dyes can reach unprecedented time scales of $\leq 30$ fs. ${ }^{[20]}$ The observed much higher values of anisotropy for less hydrophobic anions, including $\mathrm{B}\left(\mathrm{CF}_{3}\right)_{4}$, suggest that their dye salts do not form these emissive dye clusters, but tend to disperse as ion pairs isolated in polymer matrix with poor interfluorophore communication along with non-emissive dye aggregates. 


\section{Single-particle emission properties}

We then studied our dye-loaded NPs at the single-particle level. To this end, freshly prepared non-dialyzed NPs were immobilized at the glass surface and imaged using wide-field fluorescence microscopy. NPs with small hydrophilic counterions were not tested because they produced particle aggregation. Fluorescent particles were observed as bright spots, distributed randomly on the surface (Figure $5 \mathrm{~A}$ ). The best quality images were obtained for $\mathrm{B}_{21} \mathrm{H}_{18}, \mathrm{~F} 5$ TPB, F6-TPB and F12-TPB (Figure 5A and Figure S30), where particles appeared bright on a relatively dark background. For $\mathrm{B}\left(\mathrm{CF}_{3}\right)_{4}$ the background signal was higher, probably because some fraction of poorly encapsulated dyes desorbed from particles, producing some background noise. The images of quantum dots QD585 remained relatively dim despite the use of even higher excitation power, showing that all our NPs are much brighter than QD585. Quantitative analysis revealed that all our NPs were 20-40-fold brighter than QD585 particles at the same instrumental settings. Previous studies showed that high brightness of NPs could be achieved using R18 salt with F5-TPB ${ }^{[16]}$ and an aluminate $\mathrm{F} 9-\mathrm{Al}^{[18]}$ counterions. Here, we show that other counterions of very different structure can operate similarly to F5-TPB. Particularly interesting in this respect are $\mathrm{B}_{21} \mathrm{H}_{18}$ and $\mathrm{B}\left(\mathrm{CF}_{3}\right)_{4}$. The former is the first example of a non-fluorinated anion capable to prevent ACQ of R18, while the latter is by far the smallest fluorinated anion that prevents ACQ despite being >2-fold smaller than F5-TPB. 
A
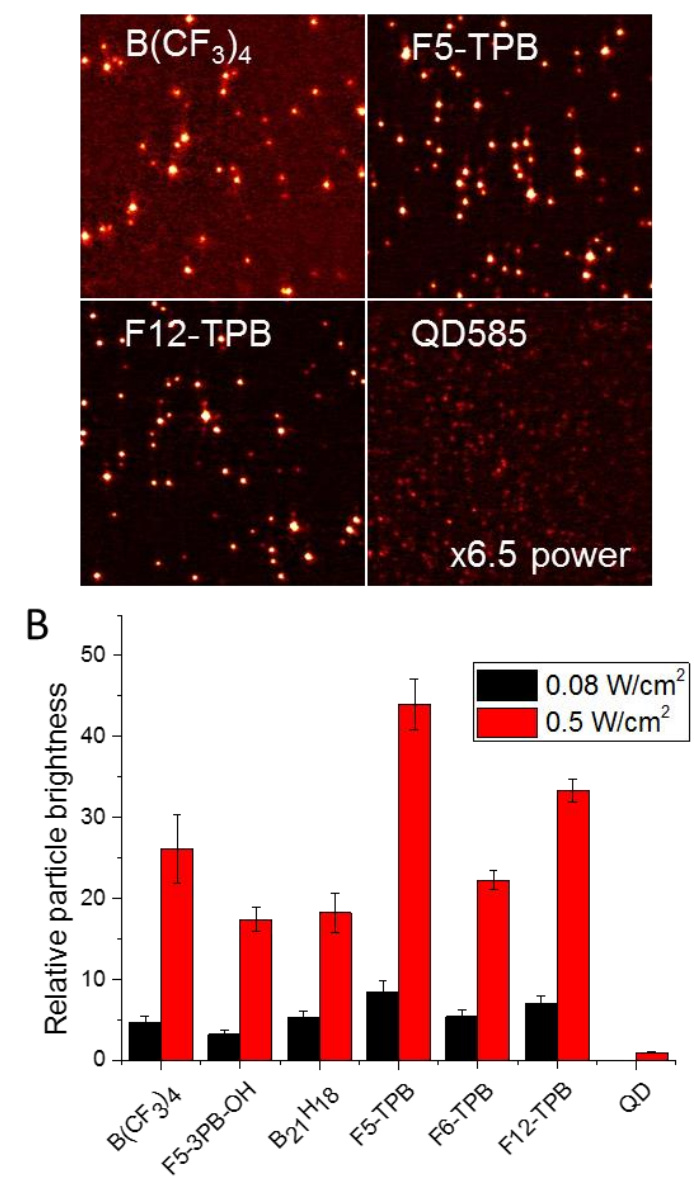

Figure 5. Single-particle characterization of dye-loaded polymer NPs by wide-field fluorescence microscopy. (A) Microscopy images of some of the dye-loaded polymer NPs in comparison to quantum dots QD585. Excitation wavelength was $532 \mathrm{~nm}$ with power density of $0.08 \mathrm{~W} / \mathrm{cm}^{2}\left(0.5 \mathrm{~W} / \mathrm{cm}^{2}\right.$ for QDs). Integration time was $305 \mathrm{~ms}$. Image size was $27 \times 27 \mu \mathrm{m}$. (B) Single-particle brightness of dye-loaded polymer NPs measured at two different excitation power densities. The values are relative to the brightness of a single QD585 at $0.5 \mathrm{~W} / \mathrm{cm}^{2}$. Errors are standard deviation of the mean for 3 images. At least 200 particles per image were analyzed in each condition.

Next, we analyzed the fluorescence intensity of single particles as a function of time. With some counterions, such as $\mathrm{B}\left(\mathrm{CF}_{3}\right)_{4}$ and $\mathrm{F} 5-3 \mathrm{~PB}-\mathrm{OH}$, NPs showed stable fluorescence, whereas for all others a complete ON/OFF switching was observed (Figure 6A). The latter was previously reported for NPs loaded with R18/F5-TPB, ${ }^{[16]}$ and was assigned to unprecedented communication of R18 dyes, assembled inside the polymer matrix by the F5-TPB counterion. The counterion plays the role of both spacer, which prevents dyes from ACQ, and "glue" that brings the dyes together and ensures fast EET. ${ }^{[16-17,20]}$ In these conditions, any transient dark species inside a particle can quench the entire particle. Here, we showed that this unique ON/OFF switching behavior of a large dye ensemble is realized for different types of counterions: three from fluorinated TPB and one from the borohydride family. A remarkable observation in this respect is a complete absence of the ON/OFF switching behavior for $\mathrm{B}\left(\mathrm{CF}_{3}\right)_{4}$ and $\mathrm{F} 5-3 \mathrm{~PB}-\mathrm{OH}$. The size of these two anions is significantly smaller and they are significantly less hydrophobic (i.e. lower $\log _{\mathrm{HWA}}$ and $\mathrm{Rf}$ values) compared to the fluorinated TPBs. The absence of blinking also matches well the high values of fluorescence anisotropy 
observed for these two counterions (Figure 4B, Table S5), confirming that for these anions the dye-dye communication through EET is clearly less efficient as compared to the fluorinated TPBs. Thus, by varying the counterion nature we can tune the NP emission from complete ON/OFF switching to stable emission.
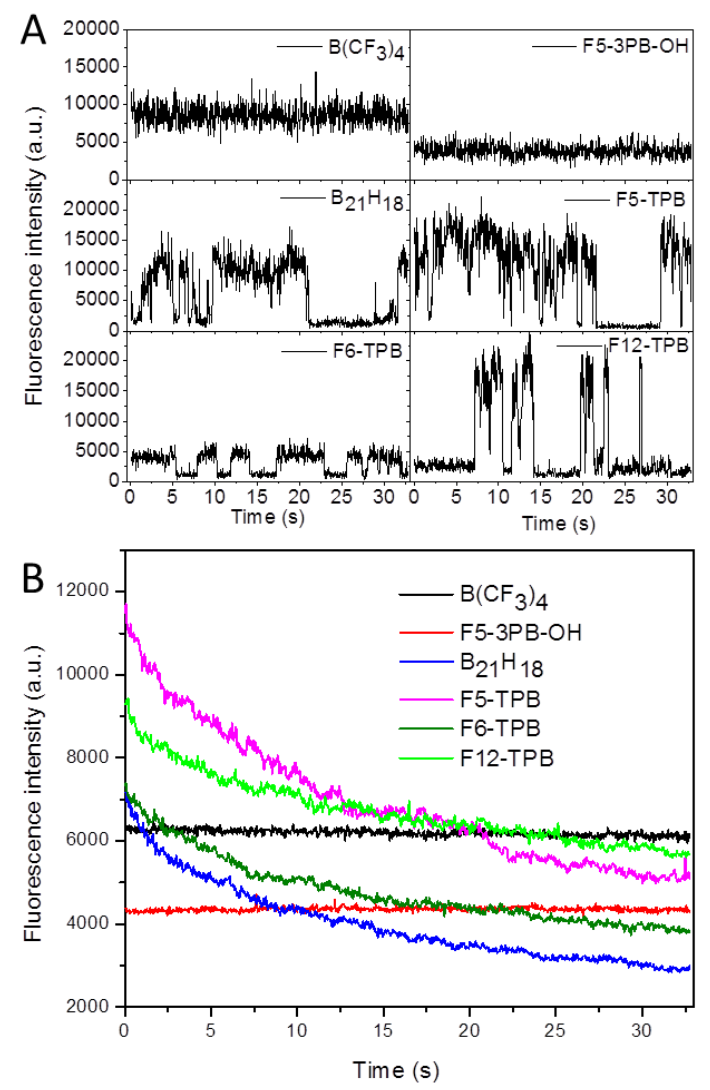

Figure 6. Single-particle emission traces (A) and photostability (B) of dye-loaded NPs containing R18 dye salts with different counterions, studied under wide-field microscopy. (A) Fluorescence intensity traces of representative single NPs recorded at integration time of $30.5 \mathrm{~ms}$. Excitation wavelength was $532 \mathrm{~nm}$ with power density of $0.08 \mathrm{~W} / \mathrm{cm}^{2}$. (B) Fluorescence intensity recorded for all particles within an image as a function of time.

Photostability of these NPs was also monitored with the same wide-field setup by recording the average fluorescence intensity of all detected NPs as a function of time (Figure 6B). These studies revealed that all NPs, demonstrating ON/OFF switching behavior, showed continuous decay of fluorescence, clearly due to conversion of the NPs into the dark state. In all these cases, dark species accumulate within the particles, which further leads to complete loss of their fluorescence. In sharp contrast, NPs containing $\mathrm{B}\left(\mathrm{CF}_{3}\right)_{4}$ and $\mathrm{F} 5-3 \mathrm{~PB}-\mathrm{OH}$, which did not undergo ON/OFF switching, showed stable fluorescence without clear signs of fluorescence decay. These results show that the counterions with medium size and hydrophobicity minimize dye-dye energy transfer and ensure higher photostability of their NPs. 


\section{Cellular studies}

Finally, we incubated our NPs with living cells in order to evaluate their compatibility with cell imaging applications. In this case we tested NPs with all the counterions, including small hydrophilic ones, to see if their poor encapsulation capacity would influence the cell staining profile. Fluorescence confocal microscopy images of KB cells, incubated with NPs, showed dramatic differences for NPs containing different counterions (Figure 7, Figure S31). Indeed, for NPs containing bulky hydrophobic fluorinated TPBs, dotted fluorescence of NPs was observed inside the cells, in line with earlier works showing that these small PLGA NPs enter cells by endocytosis. ${ }^{[16,18]}$ On the other hand, for small hydrophilic anions continuous fluorescence was observed all over cells without any signs of particle fluorescence, suggesting strong dye leakage from NPs (Figure 7 and Figure S31). We expect that the non-encapsulated dye desorbs from NPs surface due to contact with cell membranes and then gets dissolved in lipids of membranes, generating high fluorescence signal all over the cells. The observed significantly higher fluorescence intensity in this case is due to much higher efficiency of contact-mediated dye transfer from all NPs outside and inside the cells comparing to endocytosis of NPs, ${ }^{[39]}$ in agreement with our previous work. ${ }^{[19]}$ The intermediate case was observed for NPs containing $\mathrm{B}\left(\mathrm{CF}_{3}\right)_{4}, \mathrm{~F} 5-3 \mathrm{~PB}-\mathrm{OH}$ and $\mathrm{B}_{21} \mathrm{H}_{18}$, where both continuous fluorescence from the leaked dye and dotted fluorescence from NPs were observed. These results show that only in the case of highly fluorinated TPBs, especially F6-TPB and F12-TB, no leakage was detected, whereas in all other cases, the surface-bound dyes detached from the NP surface and spread all over the cells. This conclusion is in line with our encapsulation studies showing that only fluorinated TPBs exhibit the capacity to encapsulate the cationic R18 dye with nearly quantitative efficiency. Remarkably, an encapsulation efficiency of 0.92 in case of F5-TPB was still not sufficient, as for high loading some dye release was still observed (Figure 7). We further performed the same cell imaging studies using $\mathrm{B}\left(\mathrm{CF}_{3}\right)_{4}$ (Figure S32) and F5-TPB (Figure S33) NPs after purification by dialysis with beta-cyclodextrin. It could be seen that purification drastically decreased intracellular emission background from the free dye. These results show, that removal of the poorly encapsulated fraction of dyes from the NP surface can significantly decrease the amount of released dye in biological media. 


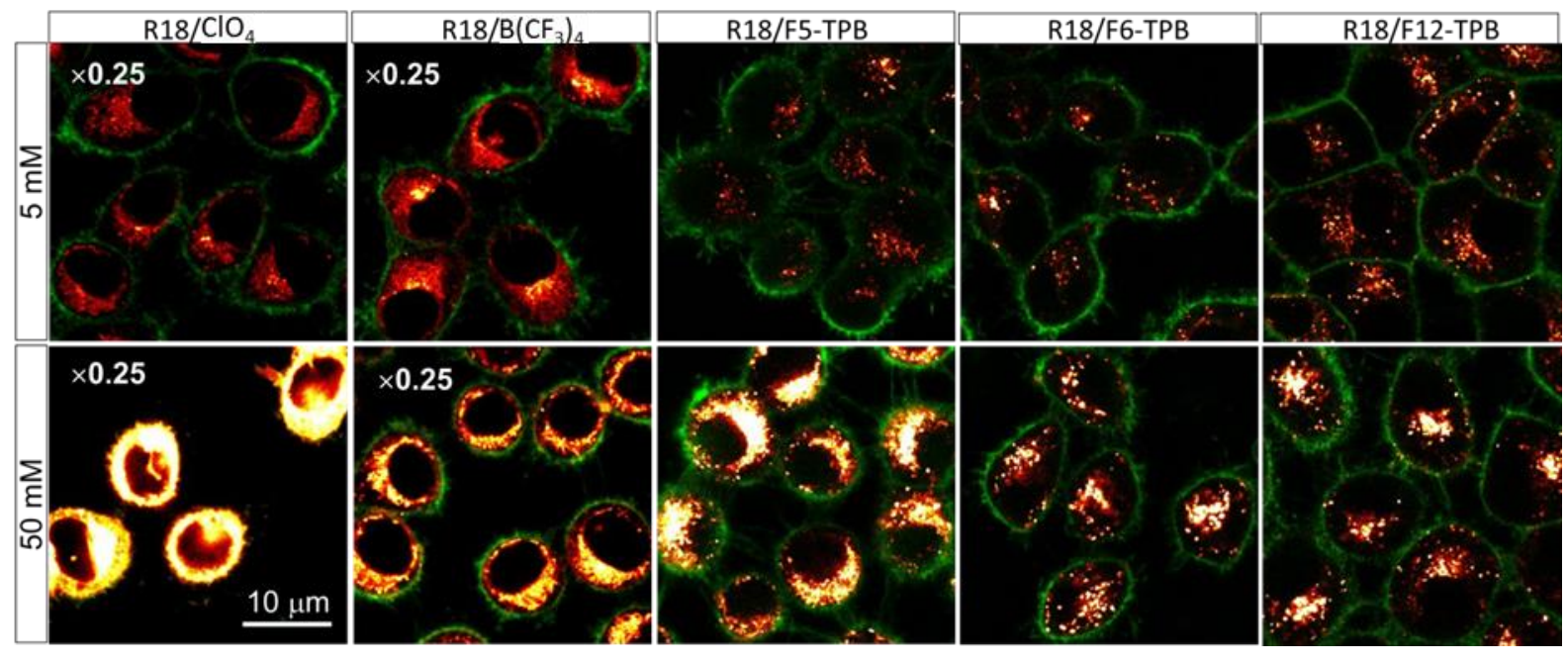

Figure 7. Confocal images of KB cells, incubated for $3 \mathrm{~h}$ with dye-loaded PLGA NPs. NPs were loaded at the concentration of 5 and $50 \mathrm{mM}$ with R18 salts with different counterions. Excitation was done with $561 \mathrm{~nm}$ laser, emission was collected from 570 to $650 \mathrm{~nm}$. For R18/ClO 4 and $\mathrm{R} 18 / \mathrm{B}\left(\mathrm{CF}_{3}\right)_{4} \mathrm{NPs}$ at both loadings the brightness was decreased 4 times for better visibility. Membranes were stained with wheat-germ agglutinin-Alexa488 (in green). The excitation was done at $488 \mathrm{~nm}$, emission was collected from 500 to $550 \mathrm{~nm}$.

\section{Role of a counterion in dye encapsulation and emission}

During nanoprecipitation the interdiffusion of water and acetonitrile leads to supersaturation of the organic compounds. ${ }^{[40]}$ In our case, supersaturation of polymer and the dye salt, driven by hydrophobic forces results in nanoprecipitation of both components together. Therefore, encapsulation of the dye salt should depend on its hydrophobicity. According to chromatography (Rf) and phase partitioning ( $\left.\log \mathrm{P}_{\mathrm{HWA}}\right)$, the most apolar and hydrophobic dye salts are formed by the largest and most fluorinated counterions. These salts will have the strongest tendency to interact with hydrophobic matrix of PLGA polymer, thus explaining their better encapsulation and lowest leakage in living cells. On the other hand, for all other counterions, the dye salts are much less hydrophobic, as could be seen from low values LogPнwa and Rf. In these cases, polymer could precipitate at the same time or even faster than the dye salt, thus resulting in some fraction of the dyes being located at the surface of polymer NPs without efficient encapsulation (Figure 3). Moreover, in case of the smallest and most hydrophilic anions, the dye salts could additionally dissociate in aqueous media. Then, generated cationic R18 dye being adsorbed at the NPs surface could decrease their negative surface charge (Figure 8) and, thus, compromise their colloidal stability as observed by DLS. Indeed, we have shown previously that the amount of charged groups on the polymers used for NP formation is crucial for the formation of small particles. ${ }^{[8,17 b]}$ The small size of polymer NPs containing R18 with bulky hydrophobic and medium-sized counterions suggests that these ion pairs probably do not dissociate in water and do not neutralize surface carboxylates. Surface binding of dyes with small hydrophilic counterions is clearly seen in cellular experiments, where dye leakage results in the fluorescence staining of the whole cell (Figure 7). This type 
of leakage is known as burst release, which is typically observed for drug-loaded nanoparticles, ${ }^{[41]}$ including those made of PLGA. ${ }^{[42]}$ Here, we showed that this burst release can be minimized by hydrophobic counterions forming ion pairs with ionic cargo.

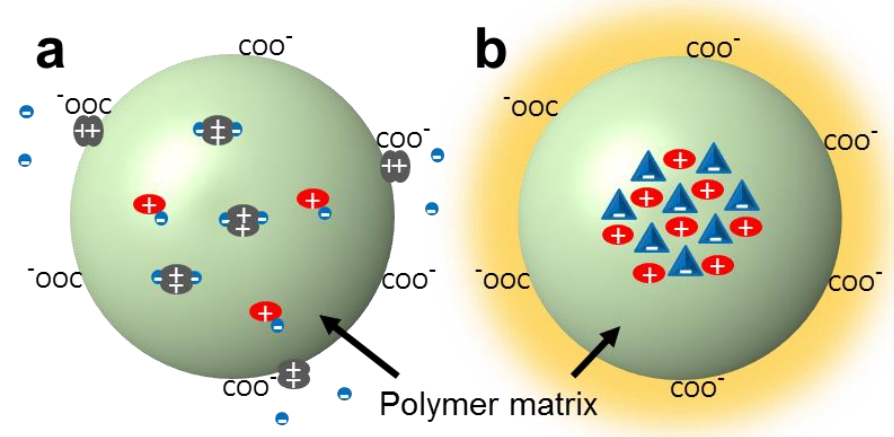

๑ Fluorescent cationic dye

Æ Non-fluorescent dye aggregate

$\mathbf{\Delta}$ Large hydrophobic anion

- Small hydrophilic anion

Weakly fluorescent

Strongly fluorescent

Figure 8. Scheme of proposed models of R18 dye distribution inside PLGA NPs for a) for ion pairs with small hydrophilic counterions, like $\mathrm{ClO}_{4}$ and b) ion pairs with large hydrophobic counterions, like fluorinated TPBs.

The second issue is the control of emission properties of dye-loaded NPs by counterion nature. We found that fluorescence quantum yields correlates well with size and hydrophobicity of counterions (Figure 4B), suggesting that the largest and the most hydrophobic counterions are the most efficient in fighting aggregation-caused quenching. In this case, counterion plays a role of bulky spacer between dyes, providing sufficient distance required to prevent quenching processes, such as electron transfer and H-aggregation. Remarkably, none of small hydrophilic counterions, including those containing fluorines $\left(\mathrm{BF}_{4}\right.$ and $\mathrm{PF}_{6}$ ), was able to prevent $\mathrm{ACQ}$, indicating that their size is insufficient to prevent undesired quenching processes. One could consider that there is a critical size, below which the counterion loses capacity to prevent ACQ. Indeed, starting from counterions of intermediate size, $\mathrm{B}\left(\mathrm{CF}_{3}\right)_{4}$ and $\mathrm{F} 5-3 \mathrm{~PB}-\mathrm{OH}$, the quantum yield drops abruptly. We could speculate that the size of the counterion should not be significantly smaller than the size of the dye. Previously, we showed both F5-TPB and F12-TPB are efficient against ACQ in cyanine 3 dye. ${ }^{[19]}$ However, larger dye cyanine 5 delivered higher quantum yields in couple with F12-TPB, which is larger than F5-TPB, which shows that critical size of counterion should be reached also for cyanines. It was also shown that fluorination of counterion plays an important role to prevent ACQ in pure dye salts of $\mathrm{R} 18^{[34 \mathrm{~d}]}$ and some cyanines. ${ }^{[19,43]}$ In this work, we found a first example of non-fluorinated counterion $\left(\mathrm{B}_{21} \mathrm{H}_{18}\right)$ that prevents well ACQ in dye-loaded NPs. This example confirms that its high hydrophobicity, evidenced by Rf and $\log \mathrm{P}_{\mathrm{HWA}}$, as well as the large size are probably the most critical factors preventing ACQ. However, earlier studies showed that relatively bulky and hydrophobic non-fluorinated tetraphenylborate (TPB) produces strong quenching of $\mathrm{R} 18 .{ }^{[16]}$ The key differences of $\mathrm{B}_{21} \mathrm{H}_{18}$ from TPB are the following. (i) It should not undergo electron transfer processes that could quench the cationic dye, unlike TPB. ${ }^{[44]}$ (ii) Its surface hydrogen atoms bear partial negative charge, while hydrogen atoms of TPB bear partial positive charge. The latter feature of $\mathrm{B}_{21} \mathrm{H}_{18}$ is similar to 
F5-TPB, where the negative charge is delocalized at the fluorine atoms on the surface of the anion. ${ }^{[22 \mathrm{a}]}$

Finally, we found that the nature of a counterion can largely modulate the interfluorophore communication, which is evident from fluorescence anisotropy (Figure 4B) and single particle blinking behavior (Figure 6). As shown in our recent work, R18/F5-TPB is so hydrophobic that during nanoprecipitation it might self-assemble even faster than PLGA, which may result in formation of nanoclusters of this dye salt, followed by formation of the polymer matrix around this cluster. ${ }^{[16,38]}$ The very small inter-fluorophore distances in these nanoclusters lead to very efficient and extremely fast energy transfer within all the dyes in the cluster. In consequence, a single transient dark state can temporally quench fluorescence emission from the whole cluster, leading to the OFF-state and, therefore, to blinking. In the present study this is probably the case for the four most hydrophobic and bulky anions, namely $\mathrm{B}_{21} \mathrm{H}_{18}, \mathrm{~F} 5-\mathrm{TPB}, \mathrm{F} 6-\mathrm{TPB}$ and F12-TPB. Formation of such dye clusters is supported by remarkably low fluorescence anisotropy (Figure 4B), implying very efficient dye-dye communication, and ON/OFF particle switching (Figure 6A), where hundreds of strongly coupled encapsulated dyes in the cluster can be turned off by single dark species. ${ }^{[8]}$ Moreover, nearly quantitative encapsulation and absence of dye leakage in cells show that these dye salts are deeply embedded inside the particle core, in line with our assumption of the core-shell organization of these NPs (Figure 8). By contrast, small hydrophilic counterions are unable to form these emissive clusters, because they cannot prevent ACQ, as evidenced by low quantum yields (Figure 4B). Here, we should clearly distinguish formation of self-quenched pi-pi stacked dye aggregates in the presence of small hydrophilic counterions and emissive clusters formed with bulky hydrophobic counterions capable of preventing ACQ (Figure 8). A significant fraction of these non-fluorescent aggregates is located at the particle surface, as can be seen from strong increase in the quantum yield after dialysis with beta-cyclodextrin (Figure 4B). The high fluorescence anisotropy observed in case of these small hydrophilic anions (Figure 4B) is probably related to remaining small fraction non-aggregated ion pairs dispersed in the polymer matrix of NPs (Figure 8). For counterions with intermediate properties, such as $\mathrm{B}\left(\mathrm{CF}_{3}\right)_{4}$ and $\mathrm{F} 5-3 \mathrm{~PB}-\mathrm{OH}$, the fraction of dispersed dye salt in the polymer matrix is probably higher, as seen from the highest values of anisotropy for these two counterions after dialysis (Figure 4B). We expect that the intermediate hydrophobicity of these salts matched that of PLGA, so that nanoprecipitation of the polymer was probably going with similar speed as encapsulation of the dye, thus dispersing the dye in the matrix without formation of emissive dye clusters (Figure 8). This hypothesis is confirmed by total absence of fluorescence ON/OFF switching at the single-particle level. This dispersed distribution ensured maximal dye-dye separation inside the polymer matrix, thus minimizing communication through EET, confirmed by relatively large values of fluorescence anisotropy (Figure 4B). We could conclude that dispersion of the dye inside the polymer can prevent ON/OFF switching of NPs and ensure their high photostability (Figure 6B). Overall, counterions can tune the organization of dyes inside the polymer matrix of NPs and thus change their emission from intermittent to stable and continuous, while ensuring high fluorescence quantum yields by preventing ACQ. This tuning will help designing bright fluorescent nanomaterials for specific applications. On one hand, NPs with clustered dyes, produced by bulky hydrophobic counterions, will be of high 
interest for superresolution imaging, light harvesting and FRET-based sensing. Indeed, we showed recently that R18 dye salt with bulky hydrophobic counterion F5-TPB loaded at high concentration in polymer NPs enables ultrafast EET at the fs time scale, producing highly efficient light-harvesting process, with antenna effect $>1000 .{ }^{[20]}$ This high dye cooperativity, favored by F5-TPB, has already enabled preparation of ultra-bright FRET platforms (100-fold brighter than corresponding quantum dots) for amplified detection of nucleic acids. ${ }^{[21]}$ On the other hand, NPs with dispersed dyes (using counterions of medium hydrophobicity, such as $\mathrm{B}\left(\mathrm{CF}_{3}\right)_{4}$ and $\left.\mathrm{F} 5-3 \mathrm{~PB}-\mathrm{OH}\right)$, which exhibit stable emission, will be of high interest as robust labels for single molecule/particle tracking and imaging applications. It is well established that brightness, photo-stability and continuous non-blinking emission of NPs are of key importance for single-particle tracking in live cells. ${ }^{[5,45]}$

\section{CONCLUSIONS}

Recently, the use of bulky hydrophobic counterions emerged as a promising approach for preventing aggregation-caused quenching of cationic dyes in polymeric nanomaterials. The present work has shed light on how the encapsulation and emission of dyes inside a polymer nanoparticle can be controlled by the counterion nature. To this end, a systematic study on ten counterions of different size and hydrophobicity with a cationic dye (rhodamine B octadecyl ester) was performed in nanoparticles prepared by nanoprecipitation of a biodegradable polymer PLGA. First of all, it was shown, that high hydrophobicity of a counterion is essential for quantitative encapsulation of cationic cargo and formation of small and colloidally stable nanoparticles. Quantitative encapsulation, achieved only with the most hydrophobic counterions, proved to be critical in the cellular imaging studies, where only nanoparticles with $>95 \%$ encapsulation efficiency showed no signs of dye leakage inside the cells. Second, the size of the counterion is essential to prevent aggregation-caused quenching of dyes in the polymer matrix, clearly because larger counterions better separate fluorophores from each other. On the other hand, small hydrophilic counterions systematically failed to prevent ACQ. Third, the nature of a counterion can tune the emission of dye-loaded NPs from stable to intermittent. Indeed, counterions with the largest size and hydrophobicity favor clustering of the dyes inside the polymer matrix, resulting in nearly complete ON/OFF switching of NPs. This type of NPs will be particularly suitable for super-resolution imaging as well as for lightharvesting and sensing applications where dye-dye energy transfer is of key importance. On the other hand, counterions with medium size and hydrophobicity favor homogeneous distribution of the dye inside polymer matrix, thus favoring stable emission of NPs, which is important for single-particle tracking applications. The obtained structure-property relationships validate the counterion-based approach as a mature concept to fight aggregation caused quenching and dye leakage in polymeric nanomaterials, which we call "counterionenhanced encapsulation and emission". In comparison to other strategies for preventing aggregation-caused quenching, the counterion-based approach has the following unique features. (1) Simple preparation, which uses basic modification of common organic dyes (introduction of alkyl chain) in combination with commercially available counterions. Here, nanoparticles are readily prepared by a rapid one-step nanoprecipitation protocol. (2) Compatibility of the approach with classical cationic dyes, such as rhodamine and cyanines, ${ }^{[18]}$ which are known for their high brightness and photostability. However, it should be mentioned 
that the method requires charged dyes, which can be considered as a limitation. (3) Possibility to tune dye-dye coupling by selecting the counterion and changing the dye loading. On one hand, this enables preparation of NPs with highly cooperative dyes undergoing ON/OFF switching and efficient energy transfer. On other hand, NPs with stable continuous fluorescence could be also prepared. The obtained results open a path to rational design of ultra-bright fluorescent nanomaterials for bioimaging, tracking and sensing applications. Moreover, the efficient encapsulation achieved with help of counterions can be extended to other ionic contrast agents and drugs for preparation of nanomaterials for theranostics.

\section{ACKNOWLEDGEMENTS}

This work is supported by the European Research Council ERC Consolidator grant BrightSens 648528. BA is supported by LabEx Chimie des Systèmes Complexes. AR is supported by the ANR JC/JC grant supertrack ANR-16-CE09-0007. Prof. Yves Mely and Prof. Pascal Didier are acknowledged for providing access to wide-field microscopy.

\section{CONFLICT OF INTEREST}

No conflicts of interest to declare.

\section{REFERENCES}

[1] a) J. Kim, Y. Piao, T. Hyeon, Chem. Soc. Rev. 2009, 38, 372; b) D. Ding, K. Li, B. Liu, B. Z. Tang, Accounts of Chemical Research 2013, 46, 2441; c) C. Wu, D. T. Chiu, Angewandte ChemieInternational Edition 2013, 52, 3086; d) O. S. Wolfbeis, Chem. Soc. Rev. 2015, 44, 4743; e) Y. Yang, Y. Chao, J. J. Liu, Z. L. Dong, W. W. He, R. Zhang, K. Yang, M. W. Chen, Z. Liu, NPG Asia Mater. 2017, 9, 11; f) T. M. Liu, J. Conde, T. Lipinski, A. Bednarkiewicz, C. C. Huang, NPG Asia Mater. 2016, 8, 25; g) P. D. Howes, R. Chandrawati, M. M. Stevens, Science 2014, 346, 1247390.

[2] a) J. E. Lee, N. Lee, T. Kim, J. Kim, T. Hyeon, Accounts of Chemical Research 2011, 44, 893; b) S. S. Kelkar, T. M. Reineke, Bioconjugate Chem. 2011, 22, 1879; c) X. W. Qu, P. H. Qiu, Y. Zhu, M. Y. Yang, C. B. Mao, NPG Asia Mater. 2017, 9, 7; d) F. Peng, Y. Y. Su, Y. L. Zhong, C. H. Fan, S. T. Lee, Y. He, Accounts of Chemical Research 2014, 47, 612; e) H. S. Peng, X. Y. Liu, G. T. Wang, M. H. Li, K. M. Bratlie, E. Cochrana, Q. Wang, J. Mat. Chem. B 2015, 3, 6856; f) Q. L. Liu, C. Jin, Y. Y. Wang, X. H. Fang, X. B. Zhang, Z. Chen, W. H. Tan, NPG Asia Mater. 2014, 6, 10; g) X. G. Gu, X. Y. Zhang, H. L. Ma, S. R. Jia, P. F. Zhang, Y. J. Zhao, Q. Liu, J. G. Wang, X. Y. Zheng, J. W. Y. Lam, D. Ding, B. Z. Tang, Advanced Materials 2018, 30; h) K. Li, B. Liu, Chem. Soc. Rev. 2014, 43, 6570; i) J. Qian, B. Z. Tang, Chem 2017, 3, 56.

[3] a) X. Michalet, F. Pinaud, L. Bentolila, J. Tsay, S. Doose, J. Li, G. Sundaresan, A. Wu, S. Gambhir, S. Weiss, Science 2005, 307, 538; b) I. L. Medintz, H. T. Uyeda, E. R. Goldman, H. Mattoussi, Nature Materials 2005, 4, 435; c) W. C. W. Chan, D. J. Maxwell, X. H. Gao, R. E. Bailey, M. Y. Han, S. M. Nie, Current Opinion in Biotechnology 2002, 13, 40.

[4] a) A. Reisch, A. S. Klymchenko, Small 2016, 12, 1968; b) S. Fery-Forgues, Nanoscale 2013, 5, 8428; c) Y. H. Chan, P. J. Wu, Part. Part. Syst. Charact. 2015, 32, 11.

[5] V. N. Kilin, H. Anton, N. Anton, E. Steed, J. Vermot, T. E. Vandamme, Y. Mely, A. S. Klymchenko, Biomaterials 2014, 35, 4950.

[6] A. Kaeser, P. H. J. Schenning Albertus, Advanced Materials 2010, 22, 2985. 
[7] a) Y. N. Hong, J. W. Y. Lam, B. Z. Tang, Chem. Soc. Rev. 2011, 40, 5361; b) J. Mei, N. L. C. Leung, R. T. K. Kwok, J. W. Y. Lam, B. Z. Tang, Chemical Reviews 2015, 115, 11718.

[8] A. Reisch, A. Runser, Y. Arntz, Y. Mely, A. S. Klymchenko, Acs Nano 2015, 9, 5104.

[9] a) A. S. Klymchenko, E. Roger, N. Anton, H. Anton, I. Shulov, J. Vermot, Y. Mely, T. F. Vandamme, Rsc Advances 2012, 2, 11876; b) G. Bastiat, C. O. Pritz, C. Roider, F. Fouchet, E. Lignieres, A. Jesacher, R. Glueckert, M. Ritsch-Marte, A. Schrott-Fischer, P. Saulnier, J. P. Benoit, J. Control. Release 2013, 170, 334; c) S. Petersen, A. Fahr, H. Bunjes, Mol. Pharm. 2010, 7, 350; d) S. Snipstad, S. Hak, H. Baghirov, E. Sulheim, Ý. Mørch, S. Lélu, E. von Haartman, M. Bäck, K. P. R. Nilsson, A. S. Klymchenko, C. de Lange Davies, A. K. O. Åslund, Cytometry Part A 2016, n/a.

[10] A. Wagh, S. Y. Qian, B. Law, Bioconjugate Chem. 2012, 23, 981.

[11] M. Shimizu, T. Hiyama, Chem.-Asian J. 2010, 5, 1516.

[12] a) R. Meallet-Renault, A. Herault, J. J. Vachon, R. B. Pansu, S. Amigoni-Gerbier, C. Larpent, Photochemical \& Photobiological Sciences 2006, 5, 300; b) F. Wurthner, Chemical Communications 2004, 1564; c) K. Trofymchuk, A. Reisch, I. Shulov, Y. Mely, A. S. Klymchenko, Nanoscale 2014, 6, 12934; d) J. L. Banal, H. Soleimaninejad, F. M. Jradi, M. Y. Liu, J. M. White, A. W. Blakers, M. W. Cooper, D. J. Jones, K. P. Ghiggino, S. R. Marder, T. A. Smith, W. W. H. Wong, J. Phys. Chem. C 2016, 120, 12952.

[13] a) S. Huang, K. Wang, S. Wang, Y. Wang, M. Wang, Advanced Materials Interfaces 2016, 3, 1600259; b) C. J. Yang, X. C. Wang, S. Huang, M. Wang, Adv. Funct. Mater. 2018, 28, 1705226.

[14] J. D. Luo, Z. L. Xie, J. W. Y. Lam, L. Cheng, H. Y. Chen, C. F. Qiu, H. S. Kwok, X. W. Zhan, Y. Q. Liu, D. B. Zhu, B. Z. Tang, Chemical Communications 2001, 1740.

[15] a) W. Qin, D. Ding, J. Z. Liu, W. Z. Yuan, Y. Hu, B. Liu, B. Z. Tang, Adv. Funct. Mater. 2012, 22, 771; b) K. Li, Z. S. Zhu, P. Q. Cai, R. R. Liu, N. Tomczak, D. Ding, J. Liu, W. Qin, Z. J. Zhao, Y. Hu, X. D. Chen, B. Z. Tang, B. Liu, Chem. Mat. 2013, 25, 4181; c) D. Ding, C. C. Goh, G. X. Feng, Z. J. Zhao, J. Liu, R. R. Liu, N. Tomczak, J. L. Geng, B. Z. Tang, L. G. Ng, B. Liu, Advanced Materials 2013, 25, 6083.

[16] A. Reisch, P. Didier, L. Richert, S. Oncul, Y. Arntz, Y. Mely, A. S. Klymchenko, Nature Communications 2014, 5, 4089.

[17] a) A. Reisch, K. Trofymchuk, A. Runser, G. Fleith, M. Rawiso, A. S. Klymchenko, Acs Applied Materials \& Interfaces 2017, 9, 43030; b) A. Reisch, D. Heimburger, P. Ernst, A. Runser, P. Didier, D. Dujardin, A. S. Klymchenko, Adv. Funct. Mater. 2018, 1805157.

[18] B. Andreiuk, A. Reisch, M. Lindecker, G. Follain, N. Peyrieras, J. G. Goetz, A. S. Klymchenko, Small 2017, 13, 13.

[19] B. Andreiuk, A. Reisch, V. G. Pivovarenko, A. S. Klymchenko, Materials Chemistry Frontiers 2017, 1, 2309.

[20] K. Trofymchuk, A. Reisch, P. Didier, F. Fras, P. Gilliot, Y. Mely, A. S. Klymchenko, Nat. Photonics 2017, 11, 657.

[21] N. Melnychuk, A. S. Klymchenko, J. Am. Chem. Soc. 2018, 140, 10856.

[22] a) I. Krossing, I. Raabe, Angew. Chem. Int. Ed. 2004, 43, 2066; b) S. H. Strauss, Chemical Reviews 1993, 93, 927.

[23] a) M. Q. Jia, M. Bandini, Acs Catalysis 2015, 5, 1638; b) T. A. Engesser, M. R. Lichtenthaler, M. Schleep, I. Krossing, Chem. Soc. Rev. 2016, 45, 789.

[24] W. E. Geiger, F. Barriere, Accounts Chem. Res. 2010, 43, 1030.

[25] a) A. B. A. Rupp, I. Krossing, Accounts Chem. Res. 2015, 48, 2537; b) M. Kaliner, T. Strassner, Tetrahedron Lett. 2016, 57, 3453; c) I. Raabe, K. Wagner, K. Guttsche, M. K. Wang, M. Gratzel, G. Santiso-Quinones, I. Krossing, Chem.-Eur. J. 2009, 15, 1966.

[26] S. Fischer, J. Schmidt, P. Strauch, A. Thomas, Angew. Chem. Int. Ed. 2013, 52, 12174.

[27] a) A. Rupp, N. Roznyatovskaya, H. Scherer, W. Beichel, P. Klose, C. Sturm, A. Hoffmann, J. Tubke, T. Koslowski, I. Krossing, Chem.-Eur. J. 2014, 20, 9794; b) W. Xu, C. A. Angell, 
Electrochem. Solid State Lett. 2001, 4, E1; c) M. L. Aubrey, J. R. Long, J. Am. Chem. Soc. 2015, 137, 13594.

[28] E. Bakker, P. Buhlmann, E. Pretsch, Chem. Rev. 1997, 97, 3083.

[29] X. J. Xie, A. Gutierrez, V. Trofimov, I. Szilagyi, T. Soldati, E. Bakker, Anal. Chem. 2015, 87, 9954.

[30] a) L. E. Chen, Y. Tan, X. F. Liu, Y. W. Chen, Nano Energy 2016, 27, 492; b) A. C. Veron, H. Zhang, A. Linden, F. Nuesch, J. Heier, R. Hany, T. Geiger, Org. Lett. 2014, 16, 1044.

[31] a) D. X. Ma, C. Zhang, Y. Qiu, L. Duan, J. Mater. Chem. C 2016, 4, 5731; b) D. X. Ma, L. Duan, Y. Qiu, J. Mater. Chem. C 2016, 4, 5051.

[32] a) A. TATIKOLOV, K. DZHULIBEKOV, L. SHVEDOVA, V. KUZMIN, A. ISHCHENKO, Journal of Physical Chemistry 1995, 99, 6525; b) P. Bouit, C. Aronica, L. Toupet, B. Le Guennic, C. Andraud, O. Maury, J. Am. Chem. Soc. 2010, 132, 4328.

[33] R. Bouchaala, L. Mercier, B. Andreiuk, Y. Mely, T. Vandamme, N. Anton, J. Goetz, A. Klymchenko, J. Control. Release 2016, 236, 57.

[34] a) T. Funada, T. Hirose, N. Tamai, H. Yao, Phys. Chem. Chem. Phys. 2015, 17, 11006; b) P. Magut, S. Das, V. Fernand, J. Losso, K. McDonough, B. Naylor, S. Aggarwal, I. Warner, J. Am. Chem. Soc. 2013, 135, 15873; c) M. Soulie, C. Carayon, N. Saffon, S. Blanc, S. Fery-Forgues, Phys. Chem. Chem. Phys. 2016, 18, 29999; d) I. Shulov, S. Oncul, A. Reisch, Y. Arntz, M. Collot, Y. Mely, A. Klymchenko, Nanoscale 2015, 7, 18198; e) I. Shulov, Y. Arntz, Y. Mely, V. Pivovarenko, A. Klymchenko, Chemical Communications 2016, 52, 7962.

[35] a) B. E., F. M., W. Helge, Zeitschrift für anorganische und allgemeine Chemie 2003, 629, 1229;

b) E. Bernhardt, M. Finze, H. Willner, Inorganic Chemistry 2011, 50, 10268; c) E. Bernhardt, D. J. Brauer, M. Finze, H. Willner, Angewandte Chemie-International Edition 2007, 46, 2927.

[36] R. A. Velapoldi, H. H. Tonnesen, J. Fluoresc. 2004, 14, 465.

[37] M. Cametti, B. Crousse, P. Metrangolo, R. Milani, G. Resnati, Chem. Soc. Rev. 2012, 41, 31.

[38] A. Reisch, K. Trofymchuk, A. Runser, G. Fleith, M. Rawiso, A. S. Klymchenko, ACS Appl. Mater. Interfaces 2017, 9, 43030.

[39] H. T. Chen, S. W. Kim, L. Li, S. Y. Wang, K. Park, J. X. Cheng, Proceedings of the National Academy of Sciences of the United States of America 2008, 105, 6596.

[40] a) S. M. D'Addio, R. K. Prud'homme, Advanced Drug Delivery Reviews 2011, 63, 417; b) F. Lince, D. L. Marchisio, A. A. Barresi, Journal of Colloid and Interface Science 2008, 322, 505.

[41] X. Huang, C. S. Brazel, J. Control. Release 2001, 73, 121.

[42] S. Fredenberg, M. Wahlgren, M. Reslow, A. Axelsson, Int. J. Pharm. 2011, 415, 34.

[43] a) H. Yao, K. Ashiba, Rsc Advances 2011, 1, 834; b) D. K. Bwambok, B. El-Zahab, S. K. Challa, M. Li, L. Chandler, G. A. Baker, I. M. Warner, Acs Nano 2009, 3, 3854.

[44] S. Murphy, X. Yang, G. B. Schuster, The Journal of Organic Chemistry 1995, 60, 2411.

[45] a) E. Genin, Z. H. Gao, J. A. Varela, J. Daniel, T. Bsaibess, I. Gosse, L. Groc, L. Cognet, M. Blanchard-Desce, Advanced Materials 2014, 26, 2258; b) F. Etoc, E. Balloul, C. Vicario, D. Normanno, D. Lisse, A. Sittner, J. Piehler, M. Dahan, M. Coppey, Nature Materials 2018, 17, 740; c) A. Reisch, D. Heimburger, P. Ernst, A. Runser, P. Didier, D. Dujardin, A. S. Klymchenko, 2018, 28, 1805157; d) L. A. Lane, A. M. Smith, T. Q. Lian, S. M. Nie, J. Phys. Chem. B 2014, 118, 14140 . 